\title{
The cost/benefit of sending cerebrospinal fluid for analysis on all lumbar punctures in pediatric acute lymphoblastic leukemia patients
}

\author{
Janet Wilson ${ }^{1}$, Mira Liebman ${ }^{2}$, and Donna Johnston ${ }^{2}$ \\ ${ }^{1}$ University of Ottawa Faculty of Medicine \\ ${ }^{2}$ Children's Hospital of Eastern Ontario
}

October 18, 2021

\begin{abstract}
Central nervous system (CNS) relapse in pediatric acute lymphoblastic leukemia (ALL) patients is uncommon. The cerebrospinal fluid (CSF) of patients with ALL is routinely sampled at each intrathecal chemotherapy treatment to screen for CNS relapse, which is both time-consuming and resource-intensive and must be completed approximately 30 times per patient throughout treatment. Our objective was to examine the cost-effectiveness of the routine screening on all CSF samples for CNS relapse in ALL patients, and to identify if CNS relapse can be detected clinically. We identified all patients diagnosed with ALL at the Children's Hospital of Eastern Ontario (CHEO) between January 2001 and June 2021. We collected the total number of CSF samples in these patients and the number of CSF samples positive for CNS relapse. An in-depth chart review on the patients who relapsed in the CNS was completed to identify their symptoms at relapse. Over the study period, 351 patients were diagnosed with ALL and underwent a total of 6515 LPs, each of which examined a CSF sample. The cost of CSF sample analysis is $\$ 14.32$, thus, the total cost for the study sample was $\$ 93,294.80$. There were 14 CNS relapses and although symptoms including headache, vomiting and fatigue were common, two patients were asymptomatic at relapse. Given the marginal cost of routine CSF screening and the lack of specific and sensitive symptoms for CNS relapse, we conclude that the routine practice of sending all CSF samples for analysis of CNS relapse in ALL patients is cost-effective and beneficial.
\end{abstract}

\section{Hosted file}

CNS Relapse Manuscript Oct. 15.docx available at https://authorea.com/users/441717/articles/ 542157-the-cost-benefit-of-sending-cerebrospinal-fluid-for-analysis-on-all-lumbarpunctures-in-pediatric-acute-lymphoblastic-leukemia-patients

\section{Hosted file}

Table 1.docx available at https://authorea.com/users/441717/articles/542157-the-costbenefit-of-sending-cerebrospinal-fluid-for-analysis-on-all-lumbar-punctures-inpediatric-acute-lymphoblastic-leukemia-patients

\section{Hosted file}

Table 2.docx available at https://authorea.com/users/441717/articles/542157-the-costbenefit-of-sending-cerebrospinal-fluid-for-analysis-on-all-lumbar-punctures-inpediatric-acute-lymphoblastic-leukemia-patients

\section{Hosted file}


Table 3.docx available at https://authorea.com/users/441717/articles/542157-the-costbenefit-of-sending-cerebrospinal-fluid-for-analysis-on-all-lumbar-punctures-inpediatric-acute-lymphoblastic-leukemia-patients 